\title{
Solvent and water retention in dental adhesive blends after evaporation
}

Yiu CKY ${ }^{1}$, Pashley $\mathrm{EL}^{2}$, Hiraishi $\mathrm{N}^{1}$, King $\mathrm{NM}^{1}$, Goracci $\mathrm{C}^{3}$, Ferrari $\mathrm{M}^{3}$, Carvalho $\mathrm{RM}^{4}$, Pashley $\mathrm{DH}^{5}$, Tay $\mathrm{FR}^{1}$

${ }^{1}$ Paediatric Dentistry and Orthodontics, Faculty of Dentistry, The University of Hong Kong, Pokfulam, Hong Kong SAR, China; ${ }^{2}$ Department of Oral Diagnosis, School of Dentistry, Medical College of Georgia, Augusta, Georgia, USA; ${ }^{3}$ Department of Dental Materials, University of Siena, Siena, Italy, ${ }^{4}$ Department of Operative Dentistry, Endodontics and Dental Materials, Bauru School of Dentistry, University of São Paulo, Bauru, SP, Brazil; ${ }^{5}$ Department of Oral Biology and Maxillofacial Pathology, School of Dentistry, Medical College of Georgia, Augusta, Georgia, USA

Running title: solvent and water retention after evaporation

Key words: acetone, ethanol, solubility parameter, resin, hydrophilicity

*Corresponding Author: Dr. Franklin R. Tay, Paediatric Dentistry and Orthodontics, The University of Hong Kong, Prince Philip Dental Hospital, 34 Hospital Road, Hong Kong SAR, China. Email: kfctay@netvigator.com; Tel: 852-28590251; Fax: 85225593803 


\section{ABSTRACT}

This study examined the extent of organic solvent and water retention in comonomer blends with different hydrophilicity (Hoy's solubility parameter for hydrogen bonding, $\delta_{\mathrm{h}}$ ) after solvent evaporation, and the extent of tracer penetration in polymerised films prepared from these resins. For each comonomer blend, adhesive/solvent mixtures were prepared by addition of [1] $50 \mathrm{wt} \%$ acetone; [2] $50 \mathrm{wt} \%$ ethanol [3] 30wt $\%$ acetone and $20 \mathrm{wt} \%$ water; and [4] $30 \mathrm{wt} \%$ ethanol and $20 \mathrm{wt} \%$ water. The mixtures were placed in glass wells and evaporated for $30-60 \mathrm{~s}$ for acetone-based resins, and 60-120 s for ethanol-based resins. The weight of the comonomer mixtures was measured before and after solvent evaporation. Resin films were prepared for transmission electron microscopy (TEM) after immersion in ammoniacal silver nitrate. The percentages of solvent and water retained in the comonomer mixtures, and between the acetone and ethanol groups were measured gravimetrically and were statistically compared. In comonomer-organic solvent mixtures, the percentage of solvent retained in acetone and ethanol-based mixtures significantly increased with hydrophilicity of the comonomer blends $(\mathrm{P}<0.05)$. In resin-organic solvent-water mixtures, significantly more solvent and water were retained in the ethanol-based mixtures $(\mathrm{P}<0.0001)$, when compared to acetone-based mixtures after $60 \mathrm{~s}$ air-drying. TEM revealed residual water being trapped as droplets in resin films containing acetone and water. Water-filled channels were seen along the film periphery of all groups and throughout the entire resin films containing ethanol and water. The addition of water to comonomer-ethanol mixtures results in increased retention of both ethanol and water because both solvents can hydrogen bond to the monomers. 


\section{INTRODUCTION}

In contemporary dentine adhesives, hydrophilic resin monomers are often dissolved in volatile solvents, such as acetone and ethanol. The inclusion of these volatile solvents aids in the displacement of water from the dentine surface, facilitating penetration of the resin monomers into the microporosities of the exposed, acid-demineralised collagen network [1-2]. The inclusion of solvent in dentine bonding has led to an increase in bond strength [3]. The presence of water is also essential for both etch-and-rinse and self-etch adhesives. In etch-and-rinse adhesives, water has a plasticising effect on the collagen fibrils and decreases the stiffness of the collapsed fibrils [4], which is important for the expansion of the dried dentine collagen [5-6]. In self-etch adhesives, it provides an ionisation medium to facilitate self-etching activity to occur [7].

Ideally, all solvents and water should be completely eliminated from the adhesive before light-curing, as they may have an adverse effect on polymerisation of the adhesive resin monomers [8]. This is achieved by allowing an evaporation time between application and curing of the adhesive resin. However, as water evaporates from the adhesive, the monomer to water ratio increases and lowers the vapour pressure of water, thus reducing the ability of water and solvents to evaporate from the adhesive [9-11]. It is likely that residual water and solvent will be trapped within the adhesive resin upon curing and this may compromise the overall bonding and the mechanical properties of the cured resin [12]. Incomplete removal of acetone from the adhesive layer of two-step total-etch adhesives resulted in poor polymerisation of resin and crack formation in the adhesive layer leading to premature bond failure [1315]. These solvent effects may further be complicated by the use of moist bonding technique and transudation of dentinal fluid under pulpal influence. With increased 
concentration of hydrophilic and ionic resin monomers in the simplified total-etch and self-etch adhesives, water may be incompletely removed and remain trapped as "bound" and "free" water at the bonded interface [16]. Two different modes of nanoleakage expressed as variable degrees of silver uptake have recently been reported in these simplified adhesives [17-18]. Water trees are morphological manifestation of "free" water trapped within the demineralised collagen matrices, while isolated silver deposits in the hybrid and adhesive layers represent "bound" water that is attached via hydrogen bonding to the hydrophilic monomers in the resin composition $[17,19]$. The retention of residual free water may produce localised area of incomplete resin polymerisation within the hybrid and adhesive layers. Together they represent porous regions within the bonded interface, which provide channels for water sorption and leaching of uncured water-soluble monomers that initiate hydrolytic degradation of resin-dentine bond. Consequently, removal of solvent and water is of prime importance for the integrity and durability of resin-dentine bond. However, the mode and duration of air-drying recommended varies with different manufacturers and little information is available on the effectiveness of air-drying on removing the solvent and water from the adhesives.

Thus, the objectives of this study were: (1) to compare the extent of organic solvent and water retention after solvent evaporation in five versions of methacrylate comonomer-organic solvent blends with increasing degree of hydrophilicity; (2) to examine with transmission electron microscopy (TEM), the extent of silver tracer penetration in polymerised resin films created from these comonomer blends after solvent evaporation. The degree of hydrophilicity of these resin blends is based on a calculation of their Hoy's solubility parameters for dispersive forces, polarity and hydrogen bonding. The null hypotheses tested were that comonomer hydrophilicity 
has no effect on the extent of water and organic solvent retention after air-drying, and that there is no difference in the pattern of tracer penetration in different comonomersolvent mixtures.

\section{MATERIALS AND METHODS}

\section{Measurement of Solvent Retention}

Five versions of comonomer blends with different degrees of hydrophilicity were evaluated in this study. The compositions and the respective Hoy's solubility parameters of each comonomer blend are shown in Table 1. For each comonomer blend, two experimental adhesive mixtures groups were prepared by addition of [1] $50 \mathrm{wt} \%$ 100\% acetone (Riedel-de Haën, Seelze, Germany) and [2] $50 \mathrm{wt} \% 100 \%$ ethanol (Merck, Darmstadt, Germany). In the second part of the study, two additional groups were formed for comonomer blends 3 to 5 by addition of [3] $30 \mathrm{wt} \% 100 \%$ acetone and $20 \mathrm{wt} \%$ water, and [4] $30 \mathrm{wt} \% 100 \%$ ethanol and $20 \mathrm{wt} \%$ water. Comonomer blends 1 and 2 were excluded from this part of the study, as they could not form a homogenous solution with water. The freshly prepared comonomersolvent adhesive mixtures were all ultra-sonicated for 2 min to ensure homogeneity. These solvated comonomer blends were stored in light-blocking, amber bottles that were further wrapped with tin foils until use.

All the weight measurements were carried out isothermally at $23^{\circ} \mathrm{C}$ and at a relative humidity of $70 \%$. In the first part of the study, $0.3 \mathrm{mg}$ of each comonomersolvent mixture (50 wt $\%$ comonomer and $50 \mathrm{wt} \%$ solvent) was placed on a glass well (15mm in diameter) using a calibrated pipette with disposable tips. The comonomersolvent mixtures were air-dried forcefully for either $30 \mathrm{~s}$ or $60 \mathrm{~s}$ for the acetone-based adhesive mixtures, and for either $60 \mathrm{~s}$ or $120 \mathrm{~s}$ for the ethanol-based mixtures at a distance of $10 \mathrm{~cm}$ from the glass well. The drying time was based on a pilot study, 
which showed that a period of $30 \mathrm{~s}$ was required to completely evaporate $0.15 \mathrm{mg}$ of $100 \%$ acetone and a period of $60 \mathrm{~s}$ for the evaporation of a similar mass of $100 \%$ ethanol at $23^{\circ} \mathrm{C}$ and $70 \%$ relative humidity. A fixed amount of $0.15 \mathrm{mg}$ of solvent was included in each adhesive mixture to allow comparison among the five experimental comonomer blends. The weight of the comonomer-solvent mixtures was measured before and after solvent evaporation using an analytical balance (AD6, Perkin Elmer, Shelton, CT) with a reproducibility of $0.01 \mathrm{mg}$. Ten specimens were measured for each comonomer-solvent mixture.

In the second part of the study, $0.5 \mathrm{mg}$ of comonomer-solvent-water (50 wt $\%$ comonomer, $30 \mathrm{wt} \%$ solvent and $20 \mathrm{wt} \%$ water) mixtures, each containing $0.15 \mathrm{mg}$ of solvent, were prepared. The changes in weight before and after evaporation were similarly recorded. The data were analysed using a statistical software package (SigmaStat Version 2.03, SPSS, Chicago, IL, USA). Percentages of organic solvent and water retained in the comonomer mixtures were compared within resin blends, and between acetone and ethanol groups, using one-way ANOVA and StudentNewman-Keuls multiple comparison tests. Statistical significance were set at $\alpha=$ 0.05. The relationship between the percentages of retained solvent and the square root of the cohesive energy density (i.e. Hildebrand's solubility parameter; $\delta_{t}$ ) of the five resin blends were evaluated by means of regression analysis.

\section{Ultrastructural Examination of Tracer Penetration into Resin Films}

Three pieces of polymerised resin films were prepared from each of the comonomer blends 3 to 5 solvated in organic solvent-water mixtures. The solvated mixtures were air-dried for $60 \mathrm{~s}$ for acetone-based adhesive mixture and $120 \mathrm{~s}$ for the ethanol-based mixtures at a distance of $10 \mathrm{~cm}$ from the glass well. Similar resin films 
were also prepared from original neat comonomer blends 3 to 5 to serve as controls. For the preparation of each resin film, two drops of either neat resin or evaporated comonomer blend from each group were placed on top of a clean glass slab. These drops were covered with a mylar sheet and a microscopic glass slide was then placed on top to enable the resin mixture to spread on its own. Light-curing was performed from the top of the glass slide for $40 \mathrm{~s}$. The polymerised resin film was gently removed from the mylar strip and immersed in $50 \mathrm{wt} \%$ ammoniacal silver nitrate solution for $48 \mathrm{~h}$ according to the silver impregnation protocol reported by Tay et al (2002) [13]. After reduction of the diamine silver ion complexes into metallic silver, the silver-impregnated films were processed for TEM examination by sandwiching each film between epoxy resins. $90 \mathrm{~nm}$ thick sections, each containing the entire cross section of a piece of resin film, and epoxy resin from above and below were prepared. They were examined unstained using a transmission electron microscope (Philips EM208S, Philips, Eindhoven, The Netherlands) operating at $80 \mathrm{kV}$.

\section{RESULTS}

The mean percentages and standard deviations of retained solvent in solvated comonomer blends 1 to 5 mixtures after evaporation are summarised in Table 2 . The percentages of acetone remaining in comonomer blends 1 to 5 after $30 \mathrm{~s}$ and $60 \mathrm{~s}$ of evaporation ranged from $8 \%$ to $12 \%$, and from $5 \%$ to $9 \%$ respectively. Conversely, the percentages of ethanol remaining in comonomer blends 1 to 5 after $60 \mathrm{~s}$ and $120 \mathrm{~s}$ of evaporation were $12-13 \%$ and $5-8 \%$ respectively. Significantly less solvent was retained in all five groups of comonomer mixtures after the extended period (i.e. $60 \mathrm{~s}$ for acetone-based mixtures and $120 \mathrm{~s}$ for ethanol-based mixtures) of evaporation $(\mathrm{P}<0.001)$, although the solvents were never completely eliminated. Significantly more ethanol was retained in solvated comonomer blends 1 and 2 after $60 \mathrm{~s}$ of air- 
blast evaporation $(\mathrm{P}<0.01)$ when compared to $30 \mathrm{~s}$ of evaporation in acetone-solvated comonomer mixtures. No significant difference in percentage of solvent retention was observed after $60 \mathrm{~s}$ of evaporation in acetone-solvated comonomer mixtures and $120 \mathrm{~s}$ of evaporation in ethanol-solvated comonomer mixtures. Comonomer blend 5 retained significantly more solvent than comonomer blend 1 after $30 \mathrm{~s}$ of evaporation in acetone-based mixtures and 120s of evaporation in ethanol-based mixtures $(\mathrm{P}<0.05)$. In general, the percentage of retained solvent increased with the hydrophilicity of the comonomer blends. A highly significant positive correlation $(\mathrm{r}=0.90 ; \mathrm{P}<0.05)$ was observed among the percentage of acetone retained in the five solvated comonomer mixtures and $\delta_{\mathrm{t}}$ of the comonomer blend after $30 \mathrm{~s}$ evaporation. A highly significant positive correlation $(\mathrm{r}=0.91 ; \mathrm{P}<0.05)$ was also observed among the percentage of ethanol retained in the five solvated comonomer mixtures and $\delta_{\mathrm{t}}$ of the comonomer blend after 60 s evaporation.

For the second part of the study, the mean percentages and standard deviations of organic solvent and water retained in organic solvent-water solvated comonomer mixtures 3 to 5 after evaporation are summarised in Table 3. The percentages of acetone and water remaining in these three groups after $30 \mathrm{~s}$ and $60 \mathrm{~s}$ of evaporation were approximately $34 \%$ and $26 \%$ respectively. Conversely, the percentages of ethanol and water in these three groups after $60 \mathrm{~s}$ and $120 \mathrm{~s}$ of evaporation were approximately $41 \%$ and $33 \%$ respectively. Additional air-drying significantly reduced the percentages of retained solvents $(\mathrm{P}<0.001)$. Significantly more residual solvent was retained in water-ethanol-based comonomer mixtures $(\mathrm{P}<0.0001)$ after $60 \mathrm{~s}$ of evaporation when compared to water-acetone-based comonomer mixtures after $30 \mathrm{~s}$ of evaporation.

TEM micrographs of silver penetration within resin films made from solvated 
comonomer blends are shown in Fig. 1 for comonomer blend 3, Fig. 2 for comonomer blend 4 and Fig. 3 for comonomer blend 5. All specimens were examined along the junction between the epoxy resin and the resin film. TEM revealed electronlucent droplets in the polymerised resin films prepared from acetone-water-solvated comonomer blend 3 mixtures (Fig. 1A). These droplets were either round or oval in shape, with sizes ranging from 1-7 $\mu \mathrm{m}$. These droplets broke off along the periphery of the resin films to form scalloped borders with dense silver deposits (Fig. 1B). No droplets were trapped in the polymerised resin films prepared from conomomer blends 3, 4, and 5- organic solvent mixtures.

A $10 \mu \mathrm{m}$ thick band of spotted silver grains could be identified along the junction between the epoxy resin and the neat comonomer blend 4 (control; Fig. 2A). Three types of silver deposition (water channels, a row of dense silver deposits and fine isolated silver deposits) were identified in the ethanol-solvated comonomer blend 4 mixture (Fig. 2B). Interconnected silver-filled channels were occasionally observed across the entire thickness of resin films prepared from the ethanol-water-solvated comonomer blend 4 mixtures (Fig 2C). Less water droplets were observed in the water-ethanol-solvated comonomer mixtures.

Similar silver tracer patterns (i.e. water channels, a dense row of isolated silver deposits and fine isolated silver grains) were observed in resin films prepared from the acetone-solvated comonomer blend 5 mixtures (Fig. 3A). The addition of water to the acetone-solvated comonomer mixtures resulted in the formation of several electron-lucent droplets in the polymerised resin films (Fig. 3B). Extremely large, electron-lucent droplets (ca. $35 \mu \mathrm{m})$, with silver deposition around their peripheries, could occasionally be seen spanning the whole thickness of the resin films (Fig. 3C). Branching tree-like silver deposits, propagating from the scalloped 
borders (Fig. 3D), were connected with the electron-lucent droplets in the resin films.

\section{DISCUSSION}

Current dentine adhesives are generally formulated with hydrophilic and hydrophobic resin monomers dissolved in solvents such as acetone, ethanol, and water or in solvent combinations [20]. Numerous studies have been carried out to examine the effects of solvent and moisture on the bond strengths to dentine [10, 2124] and nanoleakage expression [25]. However the effectiveness of air-drying on removal of organic solvent and water from the adhesive resin prior to polymerization has only been investigated recently in non-HEMA-containing, single-bottle type, onestep self-etch adhesives, in which phase separation of the water component in the form of spherical droplets was demonstrated ultrastructurally [26]. The wide variation in the composition and application procedures for commercial adhesive systems also makes direct comparisons among different systems difficult. As a result, we prepared experimental dentine adhesives formulations, by mixing neat comonomer blends of different hydrophilicity, with fixed quantities of solvent and water to enable comparison among groups.

The use of the Hoy's triple solubility parameters provides a simple method for estimating the relative contribution of dispersive $\left(\delta_{\mathrm{d}}\right)$, polar $\left(\delta_{\mathrm{p}}\right)$ and hydrogen bonding $\left(\delta_{\mathrm{h}}\right)$ forces to the total cohesive energy density $\left(\delta_{\mathrm{t}}\right)$ of polar solvents [27-28]. Such a method has contributed substantially to our understanding of solvent-collagen interaction to improve resin infiltration [29-30]. These parameters were used in this study as a means to rank the relative hydrophilicity of the five resin blends. Our results showed that the percentage of retained solvent increased with the hydrophilicity of the resin blends. Comonomer blend 5 adhesive mixtures retained significantly more solvent than comonomer 1 mixtures even after extended air-drying 
$(\mathrm{P}<0.05)$. Additionally, the pattern of silver tracer penetration was different among the adhesives mixtures. Thus, the results of the present study require rejection of the null hypotheses that conomomer hydrophilicity has no effect on the extent of water and organic solvent retention after air-drying and that there is no difference in the pattern of tracer penetration in different comonomer-solvent mixtures.

The extent of solvent and water retention in polymer networks is related to resin polarity. Resin polarity influences the number of hydrogen bonding sites and the attraction between the polymer and solvent. Bis-GMA-E in comonomer blend 1 is relatively hydrophobic as reflected by its lower $\delta_{\mathrm{h}}$ and $\delta_{\mathrm{t}}$ values. Bis-GMA in comonomer blend 2 is comparatively more hydrophilic than Bis-GMA-E as it contains two -OH groups. The replacement of the diluent monomer triethyleneglycol dimethacrylate (TEGDMA) with HEMA in comonomer blends 3-5 provides an additional -OH group for hydrogen bonding. Comonomer blends 4 (TCDM) and 5 (2MP) contain carboxyl and phosphate functional groups respectively, that allow the solvent to form additional hydrogen bonding with those polar groups. No significant difference in solvent retention was observed between acetone and ethanol following prolonged evaporation. This is consistent with the recent finding that there was no difference in loss of mass between acetone- and ethanol-based adhesives after 75 days of storage [31].

It is more difficult to remove water from ethanol-based adhesives than acetone-based adhesives prepared from comonomer blends 3 to 5 even after extended air-drying. The addition of specific amounts of water to certain organic solvents such as ethanol creates azeotrope [32], which is a mixture of two or more miscible liquids that retains the same composition in the vapour state as in the liquid state when distilled or partially evaporated under a certain pressure. As the concentration of the 
ethanol used in the present comonomer mixtures was below the concentration required to form an azeotrope with water (95.6\% ethanol, $4.4 \%$ water) [32], the ethanol would evaporate faster than water. This means the ethanol concentration can never reach the azeotrope concentration where it could facilitate water evaporation. Acetone, with a relatively high vapour pressure of $184 \mathrm{mmHg}$ at $20^{\circ} \mathrm{C}$, evaporates much faster than ethanol or water with a vapour pressure of $43.9 \mathrm{~mm} \mathrm{Hg}$ and 17.5 mmHg respectively [32-33]. Water and ethanol both hydrogen bond to monomers capable of hydrogen bonding. This helps to explain why more water and ethanol were retained in ethanol-based adhesives. An alternative explanation is that both water and ethanol can hydrogen bond to each other and to BisGMA or HEMA or TCDM or 2MP. As the organic solvents evaporate the molar concentration of the comonomers increases rapidly, that permits them to H-bond with more water and ethanol. Those molecules that are H-bonding to the monomers cannot form free droplets. As a result, less water droplets were observed in the resin films created from the resin-ethanolwater mixtures.

More water droplets were retained in the resin films from the resin-acetonewater mixtures. The solubility parameter for hydrogen bonding forces of acetone is 7 $\left(\mathrm{J} / \mathrm{cm}^{3}\right)^{1 / 2}$, compared to ethanol which is $\left[20\left(\mathrm{~J} / \mathrm{cm}^{3}\right)^{1 / 2}\right][33]$. That is, the affinity of the carbonyl group of acetone to hydrogen bond with itself or water or any functional group on monomers that are capable of hydrogen bond formation, is only about onethird that of ethanol. This is why acetone is so volatile. Acetone does not form an azeotrope with water, so it does not promote water evaporation. This is why residual water droplets were seen in the TEM images of the polymer.

TEM observation revealed the entrapment of droplets throughout the resin films made from the addition of $20 \%$ water to $30 \%$ organic solvent solvated 
comonomer blends 3 to 5 . These droplets were formed following ethanol/acetone evaporation that disturbed the solvent-monomer balance. This is in agreement with previously reported data, which showed that macroscopic phase separation of a BisGMA-based adhesive (70\% BisGMA/30\% HEMA) formulated with 45\% ethanol occurred at approximately 28 vol\% water [34]. Without organic solvent, phase separation in this formulation occurs at around 5 vol\% water. Phase separation occurred as a result of water separating from adhesive monomers [26]. Similar phase separation has also been observed in the adhesive layer bonded with two-step etchand-rinse [35] and one-step self-etch adhesives [36]. These electron-lucent droplets probably represented non-evaporated water that was trapped within the resin films, as they were only sparsely filled with silver deposits. When the water droplets were close to the surface, they broke off to form scalloped borders along the surface of the resin films. It is through these surface defects that attract clusters of silver deposits to interconnect and branch out to form additional water channels [19]. Similar water channels have been shown to form within commercial, hydrophilic adhesives when they are bonded to hydrated dentin [37-39]. Such channels provide avenues for convective movement of bulk water from dentine and contribute to the degradation of bonded interfaces over time [39].

Apart from the previously reported two major patterns of silver deposits: 1) water channels that were predominantly oriented perpendicular to the periphery of the resin film and 2) isolated silver grains that were randomly distributed in the polymerised resin, a dense row of isolated silver deposits was observed that was sandwiched between the water channels and isolated silver grains. This pattern of silver deposits was only seen in resin films prepared from organic solvent-comonomer mixtures and organic solvent-water-comonomer mixtures. They were not seen in resin 
film created from neat comonomer resins. The presence of these deposits was probably related to an increased concentration of retained solvent that were present on the surface of the resin film following evaporation. The volatile solvent was blocked from evaporating from the surface by the presence of the mylar strip. The retained solvent probably lead to poor resin polymerisation [14] and increased permeability, as reflected by the dense row of silver deposits in this region.

Retained organic solvent and water within the adhesive resin can severely compromise the structural integrity of the hybrid layer [40]. Increasing the concentration of acetone in single-bottle adhesives decreased their microtensile bond strength, with morphologic manifestations of cracks and interfacial gaps along the bonded interfaces [14]. The presence of remnant water may interfere with the polymerisation of the resin system and leave residual unreacted monomers that are more susceptible to leaching in these particular regions [41-43]. When $0.2 \mathrm{~mL}$ or more water was added per $\mathrm{mL}$ of comonomer, the conversion of bonding resin was decreased from $53.5 \%$ to $25 \%$ [8]. As little as the incorporation of $9 \%$ water in adhesive formulations has been considered to be detrimental to their mechanical properties [11]. Phase separation of water within adhesives can result in a very porous hybrid layer that is characterised by hydrophobic BisGMA-rich particles distributed in a hydrophilic HEMA-rich matrix [44]. Due to phase separation, the hydrophobic Bis-GMA monomers failed to completely penetrate the demineralised dentine [4546], leaving unprotected collagen fibrils surrounded by a potentially unstable polyHEMA hydrogel that is prone to hydrolytic [47] or enzymatic degradation [48] by oral fluids. Water sorption by the HEMA-rich phase and hydrophilic resin monomers may decrease the mechanical strength of the adhesive [49] and compromise the long-term durability of resin-dentine bond [50-51]. Further studies 
are required to investigate the effect of residual solvents on the long-term degradation of resin-dentine bonds.

\section{CONCLUSION}

Within the limits of this study, we conclude that:

1. The percentage of solvent retained in acetone-based and ethanol-based adhesive mixtures increased significantly with increasing hydrophilicity of the neat, non-solvated resin blends.

2. More organic solvent and water were retained in the ethanol-based adhesive mixtures when compared with acetone-based adhesive after evaporation.

3. The addition of water to comonomer-solvent mixtures allows water to hydrogen bond with comonomers, resulting in a large increase in retention of water in these solvated adhesive mixtures. 


\section{ACKNOWLEDGEMENTS}

This study was based on a thesis to be presented by Cynthia K.Y. Yiu to the Faculty of Dentistry, The University of Hong Kong in partial fulfilment of the requirements of the degree of Doctor of Philosophy. The comonomer blends used in this study were generously sponsored by Bisco, Inc. This work was supported by grant 10204604/07840/08004/324/01, Faculty of Dentistry, the University of Hong Kong, and by grants R01 DE04911 and R01 DE15306 from the National Institute of Dental Research (P.I. David Pashley). The authors are grateful to Mrs. Michelle Barnes and Mrs. Zinnia Ng for secretarial support. 


\section{REFERENCES}

1. Kanca J 3rd. Effect of resin primer solvents and surface wetness on resin composite bond strength to dentin. Am J Dent 1992; 5: 213-215.

2. Tay FR, Gwinnett JA, Wei SH. Micromorphological spectrum from overdrying to overwetting acid-conditioned dentin in water-free acetonebased, single-bottle primer/adhesives. Dent Mater 1996; 12: 236-244.

3. Jacobsen T, Soderholm KJ. Effect of primer solvent, primer agitation, and dentin dryness on shear bond strength to dentin. Am J Dent 1998; 11: 225228.

4. Maciel KT, Carvalho RM, Ringle RD, Preston CD, Russell CM, Pashley DH. The effects of acetone, ethanol, HEMA, and air on the stiffness of human decalcified dentin matrix. J Dent Res 1996; 75: 1851-1858.

5. Nakaoki Y, Nikaido T, Pereira PN, Inokoshi S, Tagami J. Dimensional changes of demineralized dentin treated with HEMA primers. Dent Mater 2000; 16: 441-446.

6. Carvalho RM, Yoshiyama M, Pashley EL, Pashley DH. In vitro study on the dimensional changes of human dentine after demineralization. Arch Oral Biol 1996; 4: 69-77.

7 Tay FR, Pashley DH. Aggressiveness of contemporary self-etching systems. I: Depth of penetration beyond dentin smear layers. Dent Mater 2001; 17: 296308.

8. Jacobsen T, Söderholm KJ. Some effects of water on dentin bonding. Dent Mater 1995; 11: 132-136.

9 Pashley EL, Zhang Y, Lockwood PE, Rueggeberg FA, Pashley DH. Effects of HEMA on water evaporation from water-HEMA mixtures. Dent Mater 1998; 
14: 6-10.

10. Perdigão J, Frankenberger R. Effect of solvent and rewetting time on dentin adhesion. Quintessence Int 2001; 32: 385-390.

11. Carvalho RM, Mendonca JS, Santiago SL, Silveira RR, Garcia FC, Tay FR, Pashley DH. Effects of HEMA/solvent combinations on bond strength to dentin. J Dent Res 2003; 82: 597-601.

12. Paul SJ, Leach M, Rueggeberg FA, Pashley DH. Effect of water content on the physical properties of model dentine primer and bonding resins. J Dent 1999; 27: 209-214.

13. Dickens $\mathrm{SH}$, Cho BH. Interpretation of bond failure through conversion and residual solvent measurements and Weibull analyses of flexural and microtensile bond strengths of bonding agents. Dent Mater 2005; 21: 354-64.

14. Cho BH, Dickens SH. Effects of the acetone content of single solution dentin bonding agents on the adhesive layer thickness and the microtensile bond strength. Dent Mater 2004; 20: 107-115.

15. Zheng L, Pereira PN, Nakajima M, Sano H, Tagami J. Relationship between adhesive thickness and microtensile bond strength. Oper Dent 2001; 26: 97104.

16. Klotz J, Brostow W, Hess M, Veeman WS. Epoxy and glass composites in water studied with ${ }^{2}$ H-NMR. Polym Eng Sci 1996; 36: 1129-1133.

17. Tay FR, Pashley DH, Yoshiyama M. Two modes of nanoleakage expression in single-step adhesives. J Dent Res 2002; 81: 472-476.

18. Tay FR, Pashley DH, Yiu C, Cheong C, Hashimoto M, Itou K, Yoshiyama M, King NM. Nanoleakage types and potential implications: evidence from unfilled and filled adhesives with the same resin composition. Am J Dent 
2004; 17: 182-190.

19. Tay FR, Pashley DH. Water treeing--a potential mechanism for degradation of dentin adhesives. Am J Dent 2003; 16: 6-12.

20. Nunes MF, Swift EJ, Perdigão J. Effects of adhesive composition on microtensile bond strength to human dentin. Am J Dent 2001; 14: 340-343.

21. Tay FR, Gwinnett JA, Wei SH. Micromorphological spectrum from overdrying to overwetting acid-conditioned dentin in water-free acetonebased, single-bottle primer/adhesives. Dent Mater 1996; 12: 236-244.

22. Reis A, Loguercio AD, Carvalho RM, Grande RH. Durability of resin dentin interfaces: effects of surface moisture and adhesive solvent component. Dent Mater 2004; 20: 669-676.

23. Pereira GD, Paulillo LA, De Goes MF, Dias CT. How wet should dentin be? Comparison of methods to remove excess water during moist bonding. $\mathbf{J}$ Adhes Dent 2001; 3: 257-264.

24. Perdigao J, Geraldeli S, Carmo AR, Dutra HR. In vivo influence of residual moisture on microtensile bond strengths of one-bottle adhesives. J Esthet Restor Dent 2002; 14: 31-38.

25. Reis AF, Arrais CA, Novaes PD, Carvalho RM, De Goes MF, Giannini M. Ultramorphological analysis of resin-dentin interfaces produced with waterbased single-step and two-step adhesives: nanoleakage expression. J Biomed Mater Res B Appl Biomater 2004; 71: 90-98.

26. Van Landuyt KL, De Munck J, Snauwaert J, Coutinho E, Poitevin A, Yoshida Y, Inoue S, Peumans M, Suzuki K, Lambrechts P, Van Meerbeek B. Monomer-solvent phase separation in one-step self-etch adhesives. J Dent Res 2005; 84: 183-188. 
27. Barton AFM. Handbook of solubility parameters, other cohesion parameters, $2^{\text {nd }}$ ed. Boca Raton, FL: CRC Press 1991; 98-103.

28. Eddleston CL, Hindle AR, Agee KA, Carvalho RM, Tay FR, Rueggeberg FA, Pashley DH. Dimensional changes in acid-demineralized dentin matrices following the use of HEMA-water versus HEMA-alcohol primers. J Biomed Mater Res A 2003; 67: 900-907.

29. Pashley DH, Agee KA, Carvalho RM, Lee KW, Tay FR, Callison TE. Effects of water and water-free polar solvents on the tensile properties of demineralized dentin. Dent Mater 2003; 19: 347-352.

30. Pashley DH, Agee KA, Nakajima M, Tay FR, Carvalho RM, Terada RS, Harmon FJ, Lee WK, Rueggeberg FA. Solvent-induced dimensional changes in EDTA-demineralized dentin matrix. J Biomed Mater Res 2001; 56: 273-81.

31. Abate PF, Rodriguez VI, Macchi RL. Evaporation of solvent in one-bottle adhesives. J Dent 2000; 28: 437- 440.

32. Lide RR, editor, CRC Handbook of Chemistry and Physics. Cleveland: Chemical Rubber Co., 1993: 6-169.

33. Burke J. In: Solubility Parameters: Theory and Application. Jensen C, Editor. AIC book and Paper Group Annual, volume 3, 1984; 13-58.

34. Spencer P, Wang Y. Adhesive phase separation at the dentin interface under wet bonding conditions. J Biomed Mater Res 2002; 62: 47-56.

35. Eliades G, Vougiouklakis G, Palaghias G. Heterogeneous distribution of single-bottle adhesive monomers in the resin-dentin interdiffusion zone. Dent Mater 2001; 17: 277-283.

36. Tay FR, King NM, Chan KM, Pashley DH. How can nanoleakage occur in self-etching adhesive systems that demineralize and infiltrate simultaneously? 
J Adhes Dent 2002; 4: 255-269.

37. Tay FR, Pashley DH, Suh B, Carvalho R, Miller M. Single-step, self-etch adhesives behave as permeable membranes after polymerization. Part I. Bond strength and morphologic evidence. Am J Dent 2004; 17: 271-278.

38. Tay FR, Frankenberger R, Krejci I, Bouillaguet S, Pashley DH, Carvalho RM, Lai CN Single-bottle adhesives behave as permeable membranes after polymerization. I. In vivo evidence J Dent 2004; 32: 611-621.

39. Tay FR, Hashimoto M, Pashley DH, Peters MC, Lai SC, Yiu CK, Cheong C Aging affects two modes of nanoleakage expression in bonded dentin J Dent Res 2003; 82: 537-541.

40. Miyazaki M, Platt JA, Onose H, Moore BK. Influence of dentin primer application methods on dentin bond strength. Oper Dent 1996; 21: 167-172.

41. Hashimoto M, Ohno H, Sano H, Kaga M, Oguchi H. In vitro degradation of resin-dentin bonds analyzed by microtensile bond test, scanning and transmission electron microscopy. Biomaterials 2003; 24: 3795-3803.

42. Hashimoto M, Ohno H, Sano H, Kaga M, Oguchi H. Degradation patterns of different adhesives and bonding procedures. J Biomed Mater Res B Appl Biomater 2003; 66: 324-330.

43. Hashimoto M, Ohno H, Sano H, Tay FR, Kaga M, Kudou Y, Oguchi H, Araki Y, Kubota M. Micromorphological changes in resin-dentin bonds after 1 year of water storage. J Biomed Mater Res 2002; 63: 306-311.

44. Wang Y, Spencer P. Hybridization efficiency of the adhesive/dentin interface with wet bonding. J Dent Res 2003; 82: 141-145.

45. Wang Y, Spencer P. Quantifying adhesive penetration in adhesive/dentin interface using confocal Raman microspectroscopy. J Biomed Mater Res 
2002; 59: 46-55.

46. Miyazaki M, Onose H, Moore BK. Analysis of the dentin-resin interface by use of laser Raman spectroscopy. Dent Mater 2002; 18: 576-580.

47. Hashimoto M, Tay FR, Ohno H, Sano H, Kaga M, Yiu C, Kumagai H, Kudou Y, Kubota M, Oguchi H. SEM and TEM analysis of water degradation of human dentinal collagen. J Biomed Mater Res B Appl Biomater 2003; 15: 287-298.

48. Pashley DH, Tay FR, Yiu C, Hashimoto M, Breschi L, Carvalho RM, Ito S. Collagen degradation by host-derived enzymes during aging. J Dent Res 2004; 83: 216-221.

49. Yiu CK, King NM, Pashley DH, Suh BI, Carvalho RM, Carrilho MR, Tay FR. Effect of resin hydrophilicity and water storage on resin strength. Biomaterials $2004 ; 25: 5789-5796$.

50. Carrilho MR, Carvalho RM, Tay FR, Pashley DH. Effects of storage media on mechanical properties of adhesive systems. Am J Dent 2004; 17: 104-108.

51. Carrilho MR, Tay FR, Pashley DH, Tjaderhane L, Marins Carvalho R. Mechanical stability of resin-dentin bond components. Dent Mater 2005; 21: $232-241$ 
Table 1 Composition and Hoy's solubility parameters of the five comonomer blends used in the study

\begin{tabular}{|c|c|c|c|c|c|c|}
\hline \multirow{2}{*}{$\begin{array}{l}\text { Comonomer } \\
\text { Blends }\end{array}$} & \multirow{2}{*}{ Composition } & \multirow{2}{*}{$\mathrm{Wt} \%$} & \multicolumn{4}{|c|}{ Hoy's solubility parameters $\left(\mathrm{J} / \mathrm{cm}^{3}\right)^{1 / 2}$} \\
\hline & & & $\delta_{\mathrm{d}}$ & $\delta_{\mathrm{p}}$ & $\delta_{\mathrm{h}}$ & $\delta_{\mathrm{t}}$ \\
\hline \multirow[t]{4}{*}{ Blend 1} & Bis-GMA-E & 70.00 & \multirow{4}{*}{14.8} & \multirow{4}{*}{9.8} & \multirow{4}{*}{6.9} & \multirow{4}{*}{19.1} \\
\hline & TEGDMA & 28.75 & & & & \\
\hline & CQ & 0.25 & & & & \\
\hline & EDMAB & 1.00 & & & & \\
\hline \multirow[t]{4}{*}{ Blend 2} & Bis-GMA & 70.00 & \multirow{4}{*}{13.9} & \multirow{4}{*}{12.0} & \multirow{4}{*}{10.3} & \multirow{4}{*}{20.9} \\
\hline & TEGDMA & 28.75 & & & & \\
\hline & CQ & 0.25 & & & & \\
\hline & EDMAB & 1.00 & & & & \\
\hline \multirow[t]{4}{*}{ Blend 3} & Bis-GMA & 70.00 & \multirow{4}{*}{13.9} & \multirow{4}{*}{12.6} & \multirow{4}{*}{12.2} & \multirow{4}{*}{22.3} \\
\hline & HEMA & 28.75 & & & & \\
\hline & CQ & 0.25 & & & & \\
\hline & EDMAB & 1.00 & & & & \\
\hline \multirow[t]{5}{*}{ Blend 4} & Bis-GMA & 40.00 & \multirow{5}{*}{13.6} & \multirow{5}{*}{12.6} & \multirow{5}{*}{11.3} & \multirow{5}{*}{21.9} \\
\hline & HEMA & 28.75 & & & & \\
\hline & TCDM & 30.00 & & & & \\
\hline & CQ & 0.25 & & & & \\
\hline & DMABA & 1.00 & & & & \\
\hline \multirow[t]{5}{*}{ Blend 5} & Bis-GMA & 40.00 & \multirow{5}{*}{13.9} & \multirow{5}{*}{12.9} & \multirow{5}{*}{12.9} & \multirow{5}{*}{23.0} \\
\hline & HEMA & 28.75 & & & & \\
\hline & $2 \mathrm{MP}$ & 30 & & & & \\
\hline & CQ & 0.25 & & & & \\
\hline & EDMAB & 1.00 & & & & \\
\hline
\end{tabular}

Abbreviations:- 2MP: Bis[2-(methacryloyloxy)ethyl] phosphate; Bis-GMA: bisphenol A diglycidyl ether dimethacrylate; Bis-GMA-E: ethoxylated bisphenol A diglycidyl ether dimethacrylate; CQ: camphorquinone; EDMAB: ethyl N,N-dimethyl-4-aminobenzoate; HEMA: 2-hydroxylethyl methacrylate; DMABA: dimethylaminobenzoic acid; TEGDMA: triethylene-glycol dimethacrylate; TCDM: di(hydroxyethylmethacrylate) ester of 5-(2,5dioxotetrahydrofurfuryl)-3-methyl-3-cyclohexene-1,2-dicarboxylic anhydride; $\delta_{\mathrm{d}}$ : dispersion component; $\delta_{\mathrm{p}}$ : polar component; $\delta_{\mathrm{h}}$ : hydrogen bonding component; $\delta_{\mathrm{t}}$ : total cohesive energy density value 
Table 2 Percentage of solvent retained in the five comonomer-organic solvent mixtures after solvent evaporation

\begin{tabular}{|c|c|c|c|c|}
\hline & \multicolumn{2}{|c|}{$50 \%$ comonomers $+50 \%$ Acetone } & \multicolumn{2}{|c|}{$50 \%$ comonomers $+50 \%$ Ethanol } \\
\hline $\begin{array}{c}\text { Comonomer } \\
\text { Blends } \\
\delta_{\mathrm{h}} \\
\left(\mathrm{J} / \mathrm{cm}^{3}\right)^{1 / 2}\end{array}$ & $\begin{array}{c}30 \mathrm{~s} \\
\text { evaporation }\end{array}$ & $\begin{array}{c}60 \mathrm{~s} \\
\text { evaporation }\end{array}$ & $\begin{array}{c}60 \mathrm{~s} \\
\text { evaporation }\end{array}$ & $\begin{array}{c}120 \mathrm{~s} \\
\text { evaporation }\end{array}$ \\
\hline $\begin{array}{c}\text { Blend } 1 \\
6.9\end{array}$ & $8.21(2.55)^{\mathrm{a}, \mathrm{A}}$ & $4.98(1.63)^{\mathrm{c}, \mathrm{B}}$ & $11.98(3.13)^{\mathrm{e}, \mathrm{C}}$ & $5.17(1.46)^{\mathrm{f}, \mathrm{B}}$ \\
\hline $\begin{array}{c}\text { Blend } 2 \\
10.3\end{array}$ & $8.97(2.07)^{\mathrm{a}, \mathrm{b}, \mathrm{A}}$ & $6.57(1.28)^{\mathrm{c}, \mathrm{d}, \mathrm{B}}$ & $12.98(3.07)^{\mathrm{e}, \mathrm{C}}$ & $6.20(1.44)^{\mathrm{f}, \mathrm{g}, \mathrm{B}}$ \\
\hline $\begin{array}{c}\text { Blend } 3 \\
12.2\end{array}$ & $10.45(3.67)^{\mathrm{a}, \mathrm{b}, \mathrm{A}}$ & $7.15(2.22)^{\mathrm{c}, \mathrm{d}, \mathrm{B}}$ & $12.99(4.01)^{\mathrm{e}, \mathrm{A}}$ & $6.60(1.86)^{\mathrm{f}, \mathrm{g}, \mathrm{B}}$ \\
\hline $\begin{array}{c}\text { Blend } 4 \\
11.3\end{array}$ & $11.75(3.37)^{\mathrm{a}, \mathrm{b}, \mathrm{A}}$ & $9.14(2.89)^{\mathrm{d}, \mathrm{B}}$ & $13.15(3.30)^{\mathrm{e}, \mathrm{A}}$ & $7.72(1.19)^{\mathrm{g}, \mathrm{B}}$ \\
\hline $\begin{array}{c}\text { Blend } 5 \\
12.9\end{array}$ & $12.21(2.39)^{\mathrm{b}, \mathrm{A}}$ & $9.06(2.75)^{\mathrm{d}, \mathrm{B}}$ & $13.17(3.28)^{\mathrm{e}, \mathrm{A}}$ & $7.14(1.66)^{\mathrm{g}, \mathrm{B}}$ \\
\hline
\end{tabular}

Values are means (standard deviations). All percents are mass \%. $\mathrm{n}=10$.

Columns identified with the same 'lowercase' superscripts are not significantly different $(p>0.05)$. Between groups identified with the same 'uppercase' superscripts are not significantly different $(\mathrm{p}>0.05)$.

$\delta_{\mathrm{h}}$ : Hoy's solubility parameters for hydrogen bonding 
Table 3 Percentage of solvent and water retained in comonomer-organic solvent-water mixtures after evaporation

$$
\begin{array}{cc}
50 \% \text { comonomers }+30 \% \text { Acetone } & 50 \% \text { comonomers }+30 \% \text { Ethanol } \\
+20 \% \text { water } & +20 \% \text { water }
\end{array}
$$

\begin{tabular}{ccccc}
$\begin{array}{c}\text { Comonomers } \\
\text { Blends } \\
\delta_{\mathrm{h}} \\
\left(\mathrm{J} / \mathrm{cm}^{3}\right)^{1 / 2}\end{array}$ & 30s evaporation & 60 s evaporation & 60 s evaporation & 120s evaporation \\
\hline $\begin{array}{c}\text { Blend } 3 \\
12.2\end{array}$ & $33.64(2.04)^{\mathrm{a}, \mathrm{A}}$ & $26.41(1.95)^{\mathrm{b}, \mathrm{B}}$ & $40.23(1.91)^{\mathrm{c}, \mathrm{C}}$ & $33.18(2.39)^{\mathrm{d}, \mathrm{A}}$ \\
\hline $\begin{array}{c}\text { Blend } 4 \\
11.3\end{array}$ & $35.02(3.84)^{\mathrm{a}, \mathrm{A}}$ & $27.21(3.19)^{\mathrm{b}, \mathrm{B}}$ & $41.23(1.95)^{\mathrm{c}, \mathrm{C}}$ & $33.94(2.57)^{\mathrm{d}, \mathrm{A}}$ \\
\hline $\begin{array}{c}\text { Blend5 } \\
12.9\end{array}$ & $34.87(1.73)^{\mathrm{a}, \mathrm{A}}$ & $26.70(1.73)^{\mathrm{b}, \mathrm{B}}$ & $41.64(1.80)^{\mathrm{c}, \mathrm{C}}$ & $32.84(2.25)^{\mathrm{d}, \mathrm{A}}$
\end{tabular}

Values are means (standard deviations). All percents are mass \%. $\mathrm{n}=10$.

Columns identified with the same 'lowercase' superscripts are not significantly different $(p>0.05)$. Between groups identified with the same 'uppercase' superscripts are not significantly different $(\mathrm{p}>0.05)$.

$\delta_{\mathrm{h}}$ : Hoy's solubility parameters for hydrogen bonding 


\section{LEGENDS OF FIGURES}

Fig.1 TEM micrographs of specimens from comonomer blend 3 (BisGMA + HEMA) immersed in $50 \mathrm{wt} \%$ ammoniacal silver nitrate for $24 \mathrm{~h}$. The resin films (R) were sandwiched between two layers of epoxy resin (E) for support during ultramicrotomy. A. Several round and oval-shaped electron-lucent droplets could be identified in resin film prepared from acetone-water solvated comonomer blend 3. B. Droplets that were close to the surface of the film broke off to form scalloped margins (arrows) at the boundary between the epoxy resin (E) and polymerised solvated resin (R). Clusters of silver grains (open arrowheads) condensed around these scalloped margins to initiate penetration into the resin film. Some fine, isolated silver grains could be found sparsely scattered within the resin.

Fig.2 TEM micrographs of specimens from comonomer blend 4 (Bis-GMA + HEMA + TCDM) immersed in $50 \mathrm{wt} \%$ ammoniacal silver nitrate for $24 \mathrm{~h}$. A. At $24 \mathrm{~h}$, a 10 $\mu \mathrm{m}$ thick band of silver grains could be identified in the resin film from neat comonomer blend 4 (control). This represented the diffusion of silver ions into the resin during which the dry polymerised resin film was immersed in ammoniacal silver nitrate solution. B. A high magnification view from ethanol-solvated comonomer blend 4 mixtures showing three distinct patterns of silver deposits extending from the surface of resin film: (1) Interconnected silver-impregnated tree-like channels (open arrow) oriented perpendicular to the surface of resin film, (2) a row of dense, isolated silver deposits (arrows) and (3) very fine isolated silver grains (open arrowheads). C. Through and through silver-filled channels (between open arrows) could be identified across the entire thickness of the resin film from ethanol-water solvated comonomer blend 4 mixtures.

Fig.3 TEM micrographs of specimen from comonomer blend 5 (Bis-GMA + HEMA 
$+2 \mathrm{MP}$ ) immersed in $50 \mathrm{wt} \%$ ammoniacal silver nitrate for $24 \mathrm{~h}$. A. Three patterns of silver deposits were identified in the resin film prepared from acetone-solvated comonomer blend 5 mixtures: (1) silver-impregnated water channels (open arrow), (2) a dense row of isolated silver deposits (arrows) and (3) very, fine isolated silver deposits (open arrowheads). B. Several round and oval-shaped electron-lucent droplets were present in the resin film from acetone-water solvated comonomer blend 5 mixtures. Scalloped borders (arrows) with heavy silver deposits were found at the periphery of the resin film. C. A very large droplet with occasional silver deposits at its periphery, was observed spanning across the entire thickness of resin film from acetone-water solvated comonomer blend 5 mixtures. D. The silver-filled droplets (open arrowheads) were connected to the tree-like silver deposits (arrows) around the periphery of the resin film from acetone-water solvated comonomer blend 5 mixtures. 